\title{
Aid Management and Coordination: Some Dilemmas ${ }^{1}$
}

\author{
Brian Van Arkadie
}

\section{The 'Dependency' Case against Aid}

Assessment of the impact of the aid system on any country inevitably involves a large element of judgement. Where a significant transfer of resources has occurred, it is unlikely that in any immediate sense the recipient nation could be poorer than it would have been without aid, although particular groups of people could be worse off (eg where massive food aid undermines the local farmer's market). However, the attack on aid from both left and right rests largely on the view that the aid system is a crucial negative influence on the recipient's policy regime, so undermining economic performance that any benefits of resource transfer are more than offset by lower growth, or more unequal income distribution.

Even a narrowly defined assessment of performance is difficult. The nature of the economies in question is such that development tasks are not easy. Some projects succeed, but many fail. In the case of Bangladesh, for example, performance appears weak as compared to monumental need, and little progress has been made in uplifting the mass of the poor. However, despite the meagre legacy with which Bangladesh was initially endowed, the direst predictions have not been realised; since 1974, famine has been avoided, post-war reconstruction carried through with the support of the international community, and modest growth in per capita output achieved. No economic miracle occurred in South Asia - but perhaps in the Bangladesh case anything better than bare survival is a little miraculous.

The outcome is ambiguous. Desperately low incomes, political problems, and the weak economic base can readily support a pessimistic view of the future. How far is aid much help, or how far is it part of the problem?

\footnotetext{
1 In working on Bangladesh I collaborated with Koen De Wilde, and drew on his considerable experience of the aid process in Bangladesh in this paper.
}

Large resources, including food, have been transferred to Bangladesh through aid, and many aid projects have been productive. The most compelling case against aid, however, derives less from the failure of particular aid projects than from the view that overall aid was a significant, even determining, influence in pushing the economy in directions inimical to longterm development, frustrating an alternative development option that promised a much better performance. This has been argued with great vigour by Rahman Sobhan [1982], a member of the Planning Commission in the early days of Bangladesh, a period of massive aid mobilisation. His views suggest a deep frustration with the outcome of that experience.

His radical critique of the aid system may be summarised as follows:

(a) It creates a powerful group of intermediaries (aid compradors, professionals, state officials), whose income is directly dependent on - and who have achieved considerable wealth from - aid flows, both by open and legal contractual arrangements and illicitly.

(b) Both because of the powerful interests thus created and because aid provides an easy option, difficult policy decisions are avoided, and appropriate steps are not taken to generate surpluses domestically to finance development and to restructure the economy to provide the basis for a less aid-dependent growth.

(c) Aid tying generates import-biased growth, frustrating the development of local capacity.

(d) Aid has placed undue influence in the hands of donors; the abridgement of national sovereignty inherent in this degree of aid dependence is objectionable per se, and the influence has been inappropriately used.

Donors might feel that aspects of this argument place them in a double bind: damned if they do and damned if they don't. Thus the aid system is criticised for promoting parasitic intermediates; yet when donors

IDS Bulletin, 1986, vol 17 no 2, Institute of Development Studies. Sussex 
mention corruption, or press for institutional reform, they step beyond the legitimate bounds of their role! Likewise, donors are accused of using imported inputs (including expensive consulting services); but when use is made of local institutions and consultants they are criticised as an aid-dependent, privileged élite.

However, the systematic critique of aid rests less on its observed impact than on a counterfactual view of the alternatives which might have emerged in its absence. Here, we find a superficial similarity between critical positions from the left (a 'moderate' exemplar being Griffin's paper in this Bulletin) and Bauerian marketoriented arguments; both offer a strong, if differing, view regarding superior development paths, which would be available but for aid. Ultimately, the validity of such critiques rests not so much on the observations regarding the existing structure as on the feasibility of the alternative programmes envisaged, in terms both of their economic potential and of their political sustainability, assuming a less dominant aid system.

For Bangladesh, Sobhan's counterfactual alternative is more self-reliant development, with vigorous policies to enhance and diversify exports; to substitute for imports; to reform the land tenure system; to 'socialise production planning and distribution of the grain surplus'; to raise savings, and to mobilise other budgetary resources for investment; to reduce subsidies to the better-off; and to increase domestic capacity utilisation through purposeful management to raise production, rather than aid flows. Externally, a shift in trade from the West towards the South and East is favoured.

A strong role is envisaged for the state, but geared to more thorough institutional change and development mobilisation than currently. Aid is seen as thwarting such an option, by supporting established interests and providing incentives to the state to pursue different goals.

Such radical criticism is the obverse to the geopolitical defence of Western aid that justifies such expenditures as a means of combating the risks of radical change. In both cases aid is seen as playing a potentially decisive role in determining the domestic political outcome. The desirability of the aiddependent outcome would depend, in turn, on the degree to which aid (a) pre-empts the need for radical change by supporting more gradual, but nevertheless real, solutions to social problems, or (b) merely bolsters opposition to change, as claimed by left criticism. However, the rather flabby, parasitic, bureaucratic structure, seen by the critics as the outcome of the aid relationship, would seem unlikely to provide an effective opposition to powerful forces in favour of social change, if they emerged.
For some donors who have supported social change and poverty alleviation programmes, left criticism may appear particularly damaging. In Bangladesh the 'like-minded donors', a significant segment of the aid community, have recognised the need for rural social change. Some programmes have had a measure of success in delivering income to target groups, but so far aid programmes have proved ineffective vehicles for rural social change; often, access to benefits reflects existing inequalities [see de Vylder and Asplund 1978]. However, the origin of rural inequality is surely not to be found in the aid programme; and it is far from evident that there was much indigenous impetus for radical social change for aid to thwart. ${ }^{2}$ Whether the crises which would have been engendered in the absence of aid would have provoked a radical alternative is (legitimate) speculation; however, the costs of crisis are far from speculative, and include deaths from famine.

The free market anti-aid case, associated above all with Bauer [1971, 1981, 1984], shares part of the left vision of the aid system as underwriting a parasitic bureaucracy, leading to inefficient economic decisions and inappropriate subsidisation. However, the counterfactual alternative here is a system with a small public sector, less government involvement in the economy, and prices more reflective of true scarcities. In particular, it is argued that an economy with less aid would have a more competitive exchange rate, and a domestic incentive system more conducive to exportled growth, generating non-agricultural employment and a sustainable growth path for the balance of payments. As compared with that option, the aid system might be seen as funding the growth of a bureaucratic apparatus which is a prime source of market distortions.

Against this view, those parts of the aid community, such as USAID, which promote free-market solutions argue that aid can be, and has been, used to promote policy reforms to reduce market 'distortions' resulting from past public policy (eg in relation to fertiliser marketing and pricing). Whatever the merits or weaknesses of laissez faire as an economic strategy, why should it be more likely without aid? More plausibly, the absence of aid would result in neither a rationally planned economy, nor 'undistorted' laissez faire, but a nastier, less effective and poorer version of existing systems. Conversely, in Bangladesh, as in many very poor countries, even substantial aid is

\footnotetext{
2 'The income distribution effects of the aid have largely been negative in that most of the aid has failed to reach the poorest groups of society; this has, however, rather been the fault of the domestic economic, political and social structure than of the aid per se' [de Vylder and Asplund, 1978:56].
} 
unlikely to prove sufficient for development; but it may be necessary for the avoidance of disaster. ${ }^{3}$

This judgment hardly offers two cheers for aid. This is because the economic and political future of Bangladesh is inherently problematic, so that the effectiveness and realism of alternative policy regimes - and the impact of aid upon any given regime - are subjects of legitimate debate. However, the practical policy issue is not 'aid or no aid'. It is: given aid, how can the aid system be improved? Elements of validity in anti-aid polemics do point to reforms.

\section{The Administrative Costs of Aid}

Aid has developed from a transitory phenomenon involving a few donors in any given country, to an elaborate and virtually permanent system, involving very many agencies in the economies of most poor countries. For Bangladesh and a number of least developed economies of sub-Saharan Africa, aid looms large in the public development budget and, particularly in the recent years of international crisis, has provided balance-of-payments support. Many public investments occur only if aid finance is available, and even the operation of existing facilities is contingent upon donor support for recurrent import requirements. Alongside the financial involvement, there is a substantial human presence: technical advisers, resident aid missions, visiting teams.

The importance of aid finance and the pervasiveness of the aid presence lends credibility to the critics who blame aid for major failings in domestic policy. This contrasts, however, with the donors' evident frustration at their failure to influence local policy, and the continual searching after new forms of policy leverage and 'dialogue'. To many donors, the claim that they decisively influence local policy has a hollow ring.

Yet both donors (who feel they have too little influence) and critics (who feel that donors have too great an effect) may be right. Aid has an important impact on the local policy-making and administrative system. Some consequences are the negative if unintended outcomes of aid procedures. Thus a strong impact of aid on policy and administrative performance may be consistent with correct donor

\footnotetext{
3 'The precise contribution of aid to development in Bangladesh is very difficult to measure. The role of aid cannot be assessed simply by apportioning it a share of the credit for improvements or of blame for the lack thereof in the Bangladesh economy. Even in Bangladesh, where aid accounts for such a large proportion of development expenditure, there are both external and domestic forces operating which are beyond the immediate control of the donors.

If all aid to Bangladesh had been eliminated, the most probable outcome would have been further deterioration and massive starvation' [Ehrhardt 1983:41, 43-44].
}

perceptions of their own impotence in promoting policy change.

Administrative capacity is as scarce a resource as capital or foreign exchange, but it is more difficult to supplement from outside. However, aid can place great demands on scarce administrative resources, and can only too easily confuse the decision-making process and contribute to atrophy of responsibility.

The large numbers of donors and the diversity of their aproaches imposes an enormous burden on recipient administrations. Bangladesh has more donors than most countries, but the order of magnitude is not very different from other heavily aided countries, such as Tanzania or Kenya, and the problems faced are quite typical. Over 1971-82, 35 bilateral donors participated in the Bangladesh aid programme. In 1981-82, there were 24 such countries (including 14 members of the OECD), six multilateral aid agencies (the Asian Development Bank, IDA, IFAD, the Islamic Development Bank, OPEC, and EEC), $16 \mathrm{UN}$ specialised agencies, and over 100 foreign-based NGOs.

Organisation of the donor varies a: great deal. Important variations are:

- The extent to which the head office delegates authority to the field office. Most donors are quite centralised, delaying planning and implementation.

- Staffing of the local office, which varies from a one-person bureau to USAID, with 35 staff members. Most donors opt for an administrative office staffed with aid-managers, with technical specialists located in the projects and programmes. If advice is needed, these experts are called in, which can confuse their roles and place them in an awkward position vis-à-vis the local authorities to whom they are responsible.

- Among bilateral donors, the position of the ministry or agency responsible for aid in the national bureaucracy of the donor country, and of the local office in relation to the embassy, varies.

Throughout the project cycle - from identification, through design, appraisal, approval, and implementation, to monitoring and evaluation - donor practice varies from agency to agency. It is difficult for the local official to develop a command over such procedural diversity (although he often has a good knowledge of the substantive local difficulties of implementation). The problem is compounded in multi-donor projects, operating under a variety of procurement procedures, legal provisions, equipment designs, etc.

The average length of stay of the donor representatives is only three years or so. The same applies for project 
experts. In recipient ministries and in many projects, there is also frequent change in local personnel. Thus the possibilities of building up a body of knowledge and a set of working relationships around the aid programme is limited. Lack of staff continuity and clearly delegated authority also make it difficult to locate responsibility for the success or failure of projects among either donor or local staff; this reduces incentives, job satisfaction, and the likelihood that promotion - or demotion - could be related to the eventual outcome of the programme.

Most countries try to lend coherence to complex aid programmes by channelling aid through one ministry, responsible for coordination of both the various donor sources and the spending agencies. However, the size of many programmes makes it difficult to maintain tight central control without erecting excessive bureaucratic constraints which would themselves unduly block implementation. Moreover, a coordinating agency will rarely have sufficient capacity to establish or enforce tight aid priorities. An official in the relevant coordinating ministry typically takes responsibility for liaison with one or more agencies and is unlikely to have the authority or knowledge to assert a view over the range of sectoral interests represented in a donor's project portfolio.

Although one ministry plays a key coordinating role, initiative in the promotion of projects is located throughout the government machinery. To enhance the possibilities of financing their own projects, the implementing agencies in many cases maintain intensive direct relations with donor representatives. The personalities of top officials in ministries and agencies play an important role in the success of the resulting lobbying process.

In this context, unsurprisingly, aid coordination by the recipient government is often seen by donors as inadequate. In part, this is a problem of technical coordinating capacity, dependent upon the availability and continuity of technical manpower. In part, it results from the formal powers of the coordinating authority and its location in the government structure.

On the donor side, there is a commitment to coordinate in principle. But it is tempered by the desire to accelerate programme implementation, and to work with particular parts of the system in the pursuit of objectives attractive to the particular agency.

Thus, whatever the technical capacity and formal controls, and despite agreement about the virtues of coordination, there is of ten an interest on both sides to by-pass or pre-empt the structure of control. This is neither surprising nor reprehensible. For the dynamic and astute manager, central control is often yet another external of formal authority; the informal structure of power and status provides particular managers and agencies with a real autonomy from coordinating controls.

At least part of the administrative weakness of which donors complain results from the demands of the aid programme itself. While there is no way to establish conclusively the impact of aid on the administrative structure, there is no evidence that the donors have addressed the question in any specific fashion. Even where donors perceive the problem, their behaviour is strongly influenced by the needs of their 'own' projects and programmes. Ultimately, each donor seeks to create the best conditions for its funded activities, without much regard for the overall effects.

Certainly, as currently administered, aid often imposes an enormous administrative burden. Too many foreign missions visit, ${ }^{4}$ too many projects are negotiated, too many files have to be moved and approved - without sufficient recognition of the costs of all this in terms of demands placed on limited administrative capacity. Donors might consider how the effectiveness of their own governments would be affected if their top financial and economic administrators had to devote a good part of the working day to placating external financial agencies.

Faced with bottlenecks in the administrative system, donors seek ways to facilitate implementation by developing their own connections with key personnel in the system, by training manpower for their 'own' projects, and in some cases by financing local costs for their projects. Also, many use their own technical assistance personnel to facilitate the drawing down of project funds or the smooth flow of commodity imports. The pattern of implementation increasingly reflects the ad hoc decisions of the several donor agencies, impeding rational economic coordination.

The great importance of aid as a government financial source, along with the multiplicity of aid agencies, goals and criteria, adds a complex dimension to public decision-making which in itself stands in the way of effective coordination within government. The energy expended in meeting the detailed and varied demands of the many donors might otherwise have been used to address the coherence of the government's programme in terms of its own goals.

Import tying is an additional source of administrative difficulty. It increases the cost of aided projects; it adds

\footnotetext{
${ }^{4}$ The author recently led a mission for an international agency to one small least-developed country, only to find a mission in place from a sister agency with essentially the same terms of reference. On completing the mission I left only to encounter a third mission with overlapping interests from yet another agency.
} 
to the complexity of procurement procedures; and it influences implementation priorities, as what is available from the 'tying' donor may not coincide with the requirements of priority projects.

Thus, while donors frequently express frustration with the ineffectivenes of government and autonomous institutions as implementing agencies, the burden of aid management and the complexities this introduces into the administrative process are an important part of the problem. Aid programmes themselves become both an incorrect influence on the administrative structure and a source of institutional proliferation.

Donors could reduce the hidden administrative costs of aid by strengthening their representation in the recipient countries: by increasing staff, raising levels of technical competence, and extending the duration of postings. Aid administration could then be decentralised, allowing local offices a high degree of autonomy in adjusting to local conditions and reducing the flow of visiting 'experts'. In the case of the World Bank, for example, far too high a proportion of its staff is located in Washington.

When aid is the major source of public investment finance, poor control or coordination of aid by the recipient government implies that the overall development programme is in turn poorly coordinated. Some might argue that, since the aid agencies insist on a high standard of project appraisal, a lack of coordination does not matter much. However, projects are by their nature localised and temporary. Moreover, project finance is limited, sometimes being available only for capital costs and/or import costs. The project design/appraisal/ approval processes are unlikely, therefore, to enable either the donor or the particular implementing agency to take account of the interrelationship between the project and future macroeconomic resource constraints, either on non-aid-financed local costs or on future recurrent costs.

Several donors, including the Bank, have responded sensibly to the ongoing financial crisis in sub-Saharan Africa by shifting emphasis to programme and import support (and rehabilitation). Many, however, still favour import-tied capital investment projects. These mean that aid can be utilised only to expand productive capacity in an economy which lacks the foreign exchange to utilise existing plant, and often even to maintain it.

Management at the project level also raises complex resource allocation issues. A powerful and wellorganised donor can insist, for 'its' project, on standards of management higher than those generally feasible in the economy; but then either scarce management resources are pre-empted for the aided project, at the cost of others; or the prescribed management standards are not met, to the frustration of the donor; or the donor must supply comprehensive project management, hoping to build local managerial competence during the project through training and counterpart programmes. However, islands of activity with differing management styles (and, possibly, incentive systems) are difficult to integrate into the overall administrative structure. The transition from donor to local management has often not been very successful.

The need to achieve acceptable levels of management within a given project is a source of one of the paradoxes of the aid process. Institutions, such as the World Bank, criticise bureaucratisation in principle, but promote it in practice, by elaborating exacting managerial and technical manpower requirements to ensure project success. This results in increasingly complex bureaucratic structures, and the ad hoc proliferation of institutions to meet the requirements of aided projects.

Many of the difficulties of project management arise because of the legitimate desire of donors to place a time limit on their involvement, passing on the project to local hands so that it can be integrated into the local institutional structure. Of course, the involvement of the donor agency in the economy is not temporary, so that after project 'completion' it moves on to finance new projects, even while projects previously financed go into decline. This is because initial project design failed to meet the necessary conditions for local operation and maintenance. As a result, there is a subsequent proliferation of 'rehabilitation' projects, or finance of 'new' projects doing once again what had been attempted earlier.

In some cases the realistic solution is to accept that project objectives can only be achieved with long-term donor involvement, and to take advantage of that recognition to enhance continuity of technical support. This is a sensible approach to agricultural research in Africa, for example, where continuity of professional manpower is particularly desirable, but where such a need cannot be met through local staffing.

A realistic view of the technical and managerial requirements of a project might also reduce the need for staff with high levels of formal qualifications, for example by utilising more fully knowledge existing in the local economy. The best local farmers may have more appropriate know-how than the 'expert' with much greater formal training.

Some aspects of donors' practice reflect their 
economic interests (notably import tying) or laws, making rigidity understandable. Many other aspects, however, reflect little more than administrative convenience, given established donor procedures. At least donors, who press recipients to reform, should try to standardise and simplify their own procedures, particularly where these reflect inertia or convenience rather than economic interest or doctrine.

\section{Policy Dialogue}

Only if aid were allocated randomly or automatically might it not influence domestic policy formulation. Given that the decisions of donors to provide more aid or less, or in one form or another, will be influenced by a view of policy requirements and effectiveness, there will be an incentive, even if implicit, to conform to donors' views. There is, however, a range of possibilities regarding the possible influence of aid on policy. At one extreme, the influence might be totally implicit, with donors' desires unstated and no conditions attached. At the other extreme is the strict conditionality of an IMF programme, where failure to meet precise, agreed policy conditions leads to an interruption in the flow of funds.

Insofar as aid is tied to projects, policy conditionality may be inherent in the choice and design of the project. Beyond this, conditions may be negotiated related to the use of policy instruments which can be argued to affect project performance, even if they are outside the project. Thus the donor could conceive of using the funding of a particular project as a level to achieve desired policy changes, with implications extending well beyond the project boundaries.

The wish to influence policy has grown as a result of the perception that many projects fail, however well designed, because of an inappropriate policy environment (eg an overvalued exchange rate). This concern has become particularly acute in relation to many African countries where extended economic crisis is perceived to require thoroughgoing policy reform. Hence there has been a growing donor interest in influencing government policy on a broad range of issues. Short of strict conditionality, that process is described as 'policy dialogue' - somewhat euphemistically, because the donors intend to improve recipient policy without much intention of critically examining relevant aid procedures and other donor policies. Understandably, donors may not wish to publicise their own mistakes; but it might encourage a more open and flexible discussion of policy if failings on both sides were laid on the table with equal frankness. For example, in 1982 the World Bank mounted a substantial study of agricultural sector policy in Tanzania, and subsequently sought a policy dialogue with the Tanzanians regarding their conclusions. However, the Bank's study lacked a critical examination either of its own or of other donors' performance, at project level or in policy advice. Yet during the 1970 s donors played a crucial role in the Tanzanian development programme. A more balanced approach would not only allow for better communication, but would also reduce the risk that donors will not learn lessons for their own aid policies from the poor performance of some African economies.

The other possible virtue of true dialogue might be to deepen donors' understanding of the political and social factors moulding economic policy decisions. How far donors are willing to listen, using dialogue to further their understanding of the constraints and objectives influencing the determination of policy, varies from place to place and donor to donor.

Some donors have an ambiguous attitude towards policy dialogue. They admit that they are trying to* influence policy. At the same time they state that, of course, the recipient is sovereign with a right to design and implement its own policies.

Should donors conduct dialogue with one voice? Coordinated leverage may appear practical where donors agree about required policy reform, even in the fact of recipient irritation. However, policy assessment is a matter of doctrine and interest, over which donors can well disagree, as well as of technical analysis about which agreement might be hoped for. Donors differ in the value they place on the free market and the private sector, or on distributional objectives; and in their geopolitical interests. Such diversity desirably increases recipient options. It would be a mistake to gloss over areas of legitimate doubt and policy difference.

Criticisms of the impact of aid which focus on the dangers of excessive dependence highlight some of the real dilemmas which arise when an aid programme becomes important enough to provide the major support of a development programme. There is an attendant risk that the primary task of government becomes the management of the aid relationship rather than development. Then the key to personal success is favourable location in relationship to aid flows rather than productive performance in the economy.

Aid can also act as an instrument to promote foreign firms, as well as to bolster particular local commercial interests. The concern articulated by aid critics and the sympathy such criticism engenders within the recipient countries reflects an understandable and legitimate local concern about possible loss of autonomy. 
Donors could well respond by recognising the dangers of an unduly obtrusive, assertive role. Ultimately, policy is more likely to be effective if it emerges from an indigenous political process. There is a risk that donors may shift the focus of policy discussion from the domestic forum to the aid negotiation arena, so that the resulting outcome is viewed as an external imposition for which responsibility is not accepted.

Should donors coordinate in policy dialogue? Recipients are naturally concerned about their possible joint leverage. ${ }^{5}$ For example, the World Bank, calling together and providing technical support for donor consultative groups, might orchestrate donor pressures for unwelcome policy changes. Since the 'Berg Report' the Bank has pressed for policy reforms about which many African governments are so unenthusiastic that they can well view Bank coordination of aid with some concern

Nevertheless, the Bank has the virtue of independence of any national commercial interest and is only indirectly responsive to the political concerns of major donors. And, by and large, consultative groups have been low-key enough, and the donors independent enough of any multilateral leadership, for concerted donor pressures not to have developed as an explicit feature of most aid relationships (see, however, Philip Daniel's paper in this Bulletin).

With perennial financial crisis forcing so many least developed countries to seek access to IMF facilities, coordination between the IMF and aid agencies takes on increasing interest. Suggestions for greater coordination between the Fund and the Bank were canvassed, for example by the US in the context of the 1985 Fund/Bank meeting in Seoul.

It is difficult to assess the IMF's past importance in coordinating aid. By and large, the Fund negotiates independently of third parties; yet it argues that the 'bill of health' provided by a Fund programme increases across to other finance, including aid. The corollary is that failure to agree with the Fund should reduce such access. The World Bank, in particular,

\footnotetext{
${ }^{5}$ Nurul Islam, having noted the potential benefits of a Bangladesh aid consortium commented that: 'The fact that a consortium would be likely to arrive at a common view about the strategies, policies and priorities for development in Bangladesh, opened up the possibility that more pressure would be exerted on her than if discussions were to be undertaken mainly on a bilateral basis. Flexibility and initiative would be lost if it were necessary to enunciate, defend and justify policies and priorities to a consortium. It would no longer be possible for Bangladesh to take advantage of the difference and divergences in emphasis and approach which undoubtedly existed among donors, particularly in relation to institutional and constitutional matters. Once an economic forum was established, the more aggressive and active donors would dominate and, unless underlying differences were very strong, individual donors would seldom stand out against the general view' [Faaland ed. 1981:22].
}

would find it difficult to agree to programme finance, for example structural adjustment lending, for a member state in unresolved disagreement with the Fund. In some instances, Fund support has lent momentum to a major aid initiative (eg in Sri Lanka following the advent of the Jayawardene administration). However, the extent and direction of influence, as between the Fund on the one hand and the Bank and bilateral donors on the other, is obscure; Fund negotiations are confidential, and much interagency consultation is informal.

Recent Tanzanian experience suggests some dangers in an enhanced Fund role. Tanzania has been actively, but unsuccessfully, negotiating with the Fund since 1981. Discussions have produced stalemate, with Tanzania unwilling to accept IMF conditions and the IMF unwilling to fund Tanzania's programme. Many substantive comments on adjustment issues are available in the literature [see Green 1983; Van Arkadie 1983; Helleiner 1983, 1985]. Comment here is limited to the dilemmas presented to donors by this dispute.

Faced with a deep economic crisis resulting both from policy mistakes and exogenous shocks, a recipient clearly has to adjust policies, eg on exchange-rates, budget, agricultural pricing, or key institutional arrangements. Donors have a right to advocate reform and a duty to examine their own performance.

A process of dialogue and policy reform was begun with the IDA-financed Tanzanian Advisory Group (1981-82) and the government's Structural Adjustment Programme (1982), and extended in subsequent budgetary, price policy and institutional measures. However, the prospects for an improved incentive system to work and for the budget to improve are very limited, in the absence of external short-run balanceof-payments finance for imported inputs and incentive goods. The stalemate in the Fund negotiations has therefore been a considerable hindrance.

Neither the Tanzanian government's policy adjustments nor any other proposed policy package is certain swiftly to restore growth and external balance. The Fund's proposals, insofar as they are known, seem unlikely to work in their own terms as a shortterm adjustment package, make no attempt to address a number of key longer-term issues, and are seen as too costly politically by the Tanzanian government. Moreover, controversy engendered by the IMF approach has almost certainly slowed down adjustments, eg in the exchange rate, compared to what would have been likely in the absence of dispute with the Fund.

The World Bank has had its own agenda of reform and 
dialogue, and its own areas of disagreement with Tanzania, but in the areas of prime IMF responsibility (notably the exchange rate) it has had to defer to the Fund, even if the logic of its own analysis might lead to different conclusions. Certainly the Bank could not be seen as providing an alternative to the Fund. Thus it has yet to mount a structural adjustment loan to Tanzania.

The bilateral donors have gone along with the Fund in urging Tanzania to accept a package on the Fund's terms, although only the Dutch have gone to the lengths of threatening to make their own lending conditional on agreement with the Fund. Bilateral donors presumably supported the Fund in part because they agreed with elements of its package and even found it convenient that the Fund should take on the burden of pushing unpopular policy changes. Certainly they were unready themselves to provide the level of balance-of-payments support which would have eliminated the need for a Fund programme.

Those donors, particularly the Scandinavians, who saw themselves as having a long-term commitment to Tanzania and were more sympathetic to the predicament of the Tanzanian government (and more optimistic regarding the policy trend) could not influence the Fund to soften its stance - sometimes because of the orthodoxy of their own Fund representatives. Anyway, probably only the leverage of its most powerful members is likely to shift the IMF management.

In the event, the failure to agree with the IMF has yet to result in any identifiable decline in bilateral support; even the Dutch stand has yet to be reflected in a decline in aid levels. Such erosion of support that has occurred reflects a more general disappointment of the great expectations which had generated such high aid in the 1970s. To date the main financial cost of stalemate has been lack of access to IMF funds and slow progress towards Bank structural adjustment lending. Nevertheless, it is a paradox that 'socialdemocratic' countries mount programmes (and concentrate on recipients) to pursue redistributive objectives, yet accept Fund programmes destructive of precisely those redistributive and social measures which initially attracted those donors.

Tanzanian policy can certainly be faulted in the light of the government's own stated goals, particularly in relation to rural development. But much had been achieved before the economic crisis (eg in relation to education and health). Presumably those who sympathised with the regime in the past should now be exploring the means of restoring growth momentum consistent with a renewed and realistic commitment to egalitarian objectives. That would require something quite different from an orthodox Fund programme, the effectiveness of which is controversial. Donors do not share the same priorities on development objectives, nor the same evaluations of economic policy instruments. The preference of donors as revealed in their aid portfolios reflects, among other things, differing views regarding development strategy. While there is much to be said for greater coordination and standardisation of the procedural aspects of aid, there is little merit in the homogenisation of donor views regarding policy, particularly when this involves marshalling support for financial orthodoxy.

\section{References}

Van Arkadie, Brian, 1983, in Karl Jansen (ed.), Monetarism, Economic Crisis and the Third World, Frank Cass, London

Bauer, P. T., 1971, Dissent on Development: studies and debates in development economies, Weidenfeld and Nicolson, London

-1981, Equality, the Third World and Economic Delusion, Weidenfeld and Nicolson, London

-1984, Reality and Rhetoric: studies in the economics of development, Weidenfeld and Nicolson, London

Ehrhardt, Roger, 1983, Canadian Development Assistance to Bangladesh, North-South Institute, Ottawa

Faaland, Just (ed.), 1981, Aid and Influence: The Case of Bangladesh, Macmillan, London

Green, R. H., 1983, in John Williamson (ed.), $I M F$ Conditionality, MIT Press, Cambridge (Mass.)

Helleiner, G. K., 1983, The IMF and Africa in the 1980s, Essays in International Finance No. 152, July, Princeton (NJ)

-1985, 'Aid and liquidity: the neglect of sub-Saharan Africa and others of the poorest in the emerging international monetary system', Journal of Development Planning No. 15

Sobhan, Rahman, 1982, The Crisis of External Dependence the political economy of foreign aid to Bangladesh, Dhaka University Press

de Vylder, Stefan and Daniel Asplund, 1978, Contradictions and Distortions in a Rural Economy - the case of Bangladesh, SIDA, Stockholm 